Published in final edited form as:

J Am Geriatr Soc. 2005 January ; 53(1): 34-39.

\title{
The Influence of Anxiety on the Progression of Disability
}

Gretchen A. Brenes, Ph.D. ${ }^{1}$, Jack M. Guralnik, M.D. ${ }^{2}$, Jeff D. Williamson, M.D. ${ }^{3}$, Linda P. Fried, M.D., M.P.H. ${ }^{4,5}$, Crystal Simpson, M.D., M.H.S. ${ }^{4}$, Eleanor M. Simonsick, Ph.D. ${ }^{4}, 6$, and Brenda W.J.H. Penninx, Ph.D. ${ }^{3}$

1 Department of Psychiatry and Behavioral Medicine, Wake Forest University School of Medicine

2 Epidemiology, Demography, and Biometry Program, National Institute on Aging

3 Sticht Center on Aging, Wake Forest University School of Medicine

4 Department of Medicine, Johns Hopkins Medical Institutions

5 Department of Epidemiology, Johns Hopkins Medical Institutions

6 Clinical Research Branch, National Institute on Aging

\section{Abstract}

Objectives-To determine the influence of anxiety on the progression of disability and examine possible mediators of the relationship.

Design-Community-based observational study.

Setting-Women's Health and Aging Study I, a prospective observational study with assessments every 6 months over 3 years.

Participants-One thousand two functionally limited women aged 65 years and older.

Measurements-Anxiety symptoms were assessed with 4 questions from the Hopkins Symptom Checklist (nervous or shaky, avoidance of certain things, tense or keyed up, fearful). Participants who reported experiencing 2 or more of these symptoms at baseline were considered anxious. Anxiety as a predictor of the onset of 4 types of disability was examined using Cox proportional hazard models. Three models were tested: an unadjusted model, a model adjusted for confounding variables (age, race, vision, number of diseases, physical performance, depressive symptoms), and a mediational model (benzodiazepine use, physical activity, emotional support).

Results-Nineteen percent of women reported 2 or more symptoms of anxiety at baseline. Unadjusted models indicate that anxiety was associated with a greater risk of worsening disability: ADL disability (Hazard Risk $=1.40,95 \%$ CI $1.10-1.79)$, mobility disability $(\mathrm{HR}=1.41,95 \% \mathrm{CI}$ 1.06-1.86), lifting disability ( $\mathrm{HR}=1.54,95 \% \mathrm{CI} 1.20-1.97)$, and light housework disability ( $\mathrm{HR}=$ $1.77,95 \% \mathrm{CI} 1.32-2.37)$. After adjusting for confounding variables, anxiety continued to predict the development of 2 types of disability: ADL disability (HR $=1.41,95 \% \mathrm{CI} 1.08-1.84)$ and light housework disability (HR $=1.56,95 \%$ CI $1.14-2.14)$. Finally, benzodiazepine and psychotropic medication use, physical activity, and emotional support were not significant mediators of the effect of anxiety on the development of a disability.

Conclusion-Anxiety is a significant risk factor for the progression of disability among older women. Studies are needed to determine if treatment of anxiety delays or prevents disability.

Correspondence: Dr. Gretchen A. Brenes, Department of Psychiatry and Behavioral Medicine, Wake Forest University School of Medicine, Medical Center Blvd., Winston-Salem, NC 25157 Phone: 336-716-4551, Fax: 336-716-6830, e-mail:gbrenes@ wfubmc.edu. Grant Support: The Women's Health and Aging Study was supported by contracts N01-AG-1-2112 and AG-09834 from the National Institute on Aging. The work of Dr. Brenes was supported through the Brooks Scholar in Academic Medicine Award and by National Institute of Mental Health Grant MH65281. 


\section{Keywords}

anxiety symptoms; disability; aged (65+)

\section{Introduction}

The effects of anxiety extend beyond that of emotional functioning. Evidence suggests that anxiety is associated with functional limitations or "a restriction in or lack of ability to perform an activity because of impairment". ${ }^{1}$ Previous work on the relationship between anxiety and role functioning has excluded older adults and has largely focused on interference with work functioning. A number of studies in younger samples have demonstrated that anxiety and work disability (e.g., days of work missed due to anxiety) are indeed related. ${ }^{2-6}$

The potential impact of anxiety on functioning or difficulty performing instrumental and basic activities of daily living in older adults has rarely been considered. Only a few studies have examined these relationships and the majority are cross-sectional, precluding the examination of anxiety as a precipitating factor. Salaffi ${ }^{7}$ studied 61 women with osteoarthritis of the knee and found that anxiety was significantly correlated with performance difficulty and activity limitation, even after statistically controlling for radiographic disease severity. More recently, Bond and colleagues ${ }^{8}$ demonstrated that anxiety was correlated with ADL disability in older adults who had sustained either a stroke or broken hip. deBeurs and colleagues ${ }^{9}$ found that anxiety was associated with increased physical disability in a sample of older adults after statistically controlling for a number of variables, including the number of chronic diseases and functional limitations.

Only two longitudinal studies were identified that examined anxiety as a predictor of physical disability. Tinetti et al. ${ }^{10}$ found that anxiety was a significant predictor of ADL disability over a 1 year period after controlling for baseline physical functioning. Sullivan et al. ${ }^{11}$ followed 198 CAD patients and also found that anxiety was predictive of functional disability.

Limitations of these studies are that participants with disability at baseline were not excluded from the analyses and there was a lack of control for baseline level of physical functioning.

Three variables may explain the relationship between anxiety and disability: physical activity, benzodiazepine and psychotropic medication use, and lack of emotional support. Anxiety may cause people to be less physically active, thereby causing disability. ${ }^{12-13}$ Another possibility is that people with anxiety are more likely to be medicated with benzodiazepines; the latter has been linked to a number of adverse health outcomes in the elderly, including declines in functional status, falls, and hip fractures. ${ }^{14-15}$ Finally, lack of emotional support, which may promote anxiety, has been linked to disability in older adults. ${ }^{16}$

The purpose of this study is to examine the impact of anxiety on the progression of disability over 3 years in a large sample of vulnerable, older women. The role of physical activity, benzodiazepine and psychotropic medication use, and emotional support as mediators of this relationship are also examined.

\section{Methods}

\section{Study Population}

Data are from the Women's Health and Aging Study I, a 3-year longitudinal study of the causes and course of disability among the one third most disabled older women living in the community. ${ }^{17}$ An age-stratified random sampling of Medicare beneficiaries in Baltimore, MD was undertaken to identify participants. A total of 5,316 women were eligible for screening 
and $81 \%$ were screened. Of these women, 1,409 were eligible for the study and 1,002 women agreed to participate. All participants were women aged 65 years and older who had difficulty in at least 2 of the following domains: mobility or exercise tolerance (e.g., walking 1/4 mile), upper extremity ability (e.g., raising arms over head), higher functioning tasks (e.g., using the telephone), or basic self-care (e.g., bathing). Participants who were cognitively impaired as indicated by a Mini Mental Status Exam ${ }^{18}$ score $<18$ were excluded. All participants were interviewed and examined by trained and certified personnel administering standardized protocols and questionnaires in their home every 6 months over the course of 3 years. This study was approved by the Institutional Review Board of Johns Hopkins University School of Medicine and the U.S. Office of Management and Budget; all participants provided written informed consent at enrollment.

\section{Measures}

Demographics-Demographic information, including age, race (white, not white), marital status (married, not married), and years of education, was obtained.

Anxiety-Anxiety symptoms were assessed with 4 questions from the Hopkins Symptom Checklist. ${ }^{19}$ Participants indicated whether they felt nervous or shaky, avoided certain things, felt tense or keyed up, and felt fearful. These 4 symptoms were chosen because they are characteristic of most anxiety disorders. Women who reported that they experienced 2 or more of these symptoms of anxiety quite a bit or extremely frequently over the past week were considered to have anxiety. Anxiety symptoms are rather stable in this sample. For instance, $54 \%$ of participants who reported anxiety symptoms at baseline also reported anxiety symptoms at the 6 month follow-up.

Depression-Depression was assessed with the Geriatric Depression Scale. ${ }^{20}$ Responses to the 30 items were summed, and women who scored 10 or greater were considered to have high depressive symptoms.

Disability-In order to capture a full range of severity and impact on function, disability in 4 areas was assessed. Participants were asked to rate their difficulty performing ADLs (bathing, dressing, eating, transferring from bed to chair, and using the toilet), walking across a room, lifting ten pounds, and performing light housework (such as doing dishes, straightening up, or light cleaning). Responses included "a little difficulty," "some difficulty," "a lot of difficulty," or "unable to do it." Consistent with previous studies, ${ }^{21-24}$ disability was considered present if the participant reported "a lot of difficulty" or inability to perform a task. 22,25

Health-related characteristics-The presence of 17 major chronic conditions was determined using standardized algorithms that incorporated participant self-report of physician diagnosis and of symptoms, physical examination findings, medications used, physician reports, and review of medical records. ${ }^{26}$ A variable representing the number of validated diseases that were present was then created. The presence of visual impairment was assessed by asking women whether they could see well enough to watch television, read a newspaper, or recognize someone across the room. The presence of a hearing problem was assessed by asking women whether they could hear well enough to use the telephone or to carry on a conversation in a crowded room.

Physical performance-In order to adjust for baseline physical function, performance was assessed using the Short Physical Performance Battery (SPPB) which consists of walking $4 \mathrm{~m}$, standing up from and sitting down in a chair 5 times, and 3 sequential standing balance tests. Participants received a score from 0 (unable to perform) to 4 (best performance) on each test, based on scoring criteria from the Established Populations for Epidemiologic Studies of the 
Elderly (EPESE). ${ }^{27}$ Scores on each test were summed to create a summary measure of physical performance that ranged from 0 to 12 , with higher scores indicating better performance.

Possible mediators-We examined 3 mediating variables which could potentially help explain the link between anxiety and disability: benzodiazepine and psychotropic medication use, physical activity, and emotional support. During the interviews, participants displayed all the medications (both prescription and over the counter) they had used within the previous 2 weeks and all medications used by participants were recorded. Interviewers transcribed the names and dosages of all medications. This method of medication ascertainment is similar to that used in other large epidemiological studies and has been shown to be reliable and valid.

28 For this report, the use of benzodiazepines and psychotropic medications were each represented by a dichotomous variable (yes/no). Physical activity was assessed by asking participants how many blocks they had walked during the last week. A median split was performed and responses are represented by a dichotomous variable: less than 5 blocks and 5 or more blocks. Emotional support was assessed by asking participants if they could have used more emotional support than they received in the last year (yes/no).

\section{Statistical Analyses}

A 2-step process was used to examine the relationship between anxiety and the progression of disability. In order to determine characteristics associated with baseline anxiety, bivariate relationships between anxiety and baseline demographics, health-related characteristics, and physical functioning were tested with t-tests or Chi square analyses. Variables that were significantly related to baseline anxiety were entered as covariates in regression analyses. In the second step, a series of proportional hazards models using Cox regression analyses were conducted. Dependent variables included the time to onset of disability in each of the 4 areas: ADLs, mobility disability, lifting disability, and light housework. Only participants who reported no disability at baseline in a particular area were included in the analyses and the first report of disability was considered the event of incident disability, regardless of the participant's status at subsequent interviews. Individuals who died or were lost to follow-up were censored after their last interview. Participants who survived with no evidence of progression of disability were censored at 3 years. Model 1 presents baseline anxiety as a predictor of worsening disability. In Model 2, age, race, vision problems, number of diseases, objective physical performance, and depression were entered as covariates. In Model 3, benzodiazepine and psychotropic medication use, physical activity, and emotional support are added to the regression analyses to determine if they are mediators of the effects of anxiety on disability.

\section{Results}

The WHAS sample consists of 1,002 disabled older women, with an average age of 78.3 years ( $\mathrm{SD}=8.1$ ). All women had at least 2 disabilities at baseline: $33.0 \%$ had an ADL disability, $16.0 \%$ had a mobility disability, $35.1 \%$ had a lifting disability, and $17.1 \%$ had a light housework disability. Nineteen percent of the sample reported 2 or more symptoms of anxiety at baseline. As shown in Table 1, anxiety symptoms were associated with race, vision, number of diseases, baseline physical performance, and depressive symptoms. White race $(\mathrm{p}=.04)$, vision problems $(\mathrm{p}=.03)$, greater comorbidity $(\mathrm{p}=.01)$, poorer physical performance $(\mathrm{p}<.001)$, and depressive symptoms $(\mathrm{p}<.001)$ were associated with anxiety. Bivariate relationships between anxiety and the mediator variables (benzodiazepine and psychotropic medication use, physical activity, and emotional support) were also examined. Anxiety was associated with greater benzodiazepine use $(\mathrm{p}<.001)$, greater psychotropic medication use $(\mathrm{p}<.001)$, and insufficient emotional support $(\mathrm{p}<.001)$. These variables were entered into a logistic regression analysis to determine their relationship with anxiety, independent of each variable. Number of comorbid 
conditions (Odds Ratio $=1.15,95 \%$ Confidence Interval 1.01-1.30), depressive symptoms $(\mathrm{OR}=4.79,95 \%$ CI 3.32-6.91), benzodiazepine use $(\mathrm{OR}=1.98,95 \% \mathrm{CI} 1.15-3.40)$, and emotional support ( $\mathrm{OR}=0.43,95 \% \mathrm{CI} 0.30-0.62$ ) had a significant relationship with anxiety independent of the other variables.

The percent of women developing another functional difficulty over the course of the study was $63.5 \%$ for any ADL, 34.3\% for mobility, $64.9 \%$ for lifting, and $29.6 \%$ for light housework. For each area of difficulty, women who expressed anxiety symptoms were more likely to report another functional difficulty in subsequent follow-ups (see Figure 1).

Table 2 presents the results of the Cox proportional hazards models. Model 1 consists of the unadjusted hazard risks of developing another functional difficulty. Anxiety was associated with a greater risk of developing difficulty in ADLs (Hazard Risk $=1.40,95 \%$ CI 1.10-1.79), mobility ( $\mathrm{HR}=1.41,95 \%$ CI $1.06-1.86)$, lifting ( $\mathrm{HR}=1.54,95 \%$ CI $1.20-1.97)$, and light housework (HR $=1.77,95 \%$ CI 1.32-2.37). (See Figure 1). After adjusting for baseline differences in age, race, vision, number of diseases, physical performance, and depressive symptoms (see Footnote 1), anxiety remains a significant predictor of developing a difficulty in ADLs ( $\mathrm{HR}=1.41,95 \%$ CI 1.08-1.84) and light housework ( $\mathrm{HR}=1.56,95 \%$ CI 1.14-2.14). The relationships between mobility difficulty (HR $=1.20,95 \%$ CI $0.90-1.63)$ and lifting (HR $=1.23,95 \%$ CI $0.94-1.60$ ) were no longer significant.

Three possible mediators of the effects of anxiety on the development of disability were considered: benzodiazepine and psychotropic medication use, physical activity, and adequate emotional support. Since there was no significant relationship between anxiety and physical activity (see Table 1), physical activity was not considered in further models. Benzodiazepine and psychotropic medication use were entered into one analysis while emotional support was entered into another regression analysis in the step containing anxiety. A variable was considered to be a mediator if it accounted for a significant proportion of the variance in disability and if it reduced the hazard risk of anxiety by $10 \%$ or more. None of the variables met these criteria. Emotional support was not related to new onset of difficulty in any of the 4 areas; the addition of benzodiazepine and psychotropic medication use was related only to new difficulty in lifting ( $\mathrm{HR}=1.79,95 \% \mathrm{CI} 1.28-2.52)$. Only benzodiazepine use was significant in this model $\left(\mathrm{X}^{2}(3)=12.12, \mathrm{p}=.007\right)$. However, it had no effect on the relationship between anxiety and disability. Thus, none of the proposed variables were significant mediators of the effect of anxiety on the progression of disability.

\section{Discussion}

Anxiety symptoms are common in older adults. The results of this study indicate that $19 \%$ of the older women in our sample experienced symptoms of anxiety, consistent with findings from community surveys. ${ }^{29-30}$ Previous research indicates that anxiety is associated with disability. $1,9-10,31$ However, these studies have largely employed cross-sectional designs which limit the ability to examine anxiety as a risk factor for functional decline. This study provides evidence that anxiety is associated with the progression of disability among vulnerable older women, independent of several potential confounding factors.

\footnotetext{
Footnote ${ }^{1}$ Significant covariates in the model predicting ADL disability include age $(\mathrm{HR}=1.02,95 \%$ CI $1.00-1.03)$ and physical performance $(\mathrm{HR}=0.87,95 \% \mathrm{CI} 0.84-0.90)$. Significant covariates in the model predicting mobility disability include age $(\mathrm{HR}=1.02$, 95\% CI 1.00-1.03), physical performance ( $\mathrm{HR}=0.76,95 \% \mathrm{CI} 0.72-0.80)$, and comorbidities ( $\mathrm{HR}=1.09,95 \% \mathrm{CI} 1.00-1.19)$. Significant covariates in the model predicting lifting disability include physical performance $(\mathrm{HR}=0.89,95 \% \mathrm{CI} 0.86-0.93)$, comorbidities $(\mathrm{HR}=$ $1.16,95 \%$ CI 1.08-1.24), and depressive symptoms ( $\mathrm{HR}=1.26,95 \%$ CI 1.01-1.58). Significant covariates in the model predicting light housework disability include age ( $\mathrm{HR}=1.02,95 \% \mathrm{CI} 1.00-1.04)$, vision ( $\mathrm{HR}=0.68,95 \% \mathrm{CI} 0.49-0.93)$, and physical performance (HR $=0.82,95 \%$ CI $0.78-0.87$ ).
} 
A key confounding factor is the presence of depressive symptoms which are often present with anxiety. ${ }^{32-33}$ Depression has been identified as a risk factor for physical disability (see Lenze et al. ${ }^{34}$ for a review). Yet, the role of anxiety in the development of disability independent of depressive symptoms has not been studied. In this study, we examined the role of anxiety as a predictor of worsening disability while controlling for depression. We found that depression was only significantly related to lifting disability. Depressive symptoms were not related to the 3 other types of disability. Anxiety, on the other hand, remained a significant predictor of ADL and light housework disabilities. Thus, these results establish anxiety as a risk factor for the progression of disability independent of depressive symptoms.

In an effort to begin to understand the effect of anxiety on disability, three possible mediators were examined: physical activity, benzodiazepine and psychotropic medication use, and lack of emotional support. The results of this study failed to provide support for these 3 variables playing a mediating role in the relationship between anxiety and disability. How then can we explain the link between anxiety and the progression of disability? Anxiety may be reflective of preterminal psychiatric phenomena that lead to disability. However, in our sample, anxiety was not found to be related to 3 -year mortality ( $p>.52$; data not shown). Somatic symptoms of anxiety may affect functional capacity. For example, feeling dizzy or shaky could make it difficult to walk across the room and do daily activities. Another possibility is that anxiety may precede physical diseases that cause disability. Anxiety is a risk factor for hypertension ${ }^{35-}$ 36 and heart disease, ${ }^{37}$ both of which could result in increased disability. Anxiety may have an effect on immune dysregulation, such as by slowing down immune responses to pathogens, thereby increasing one's susceptibility to disease. ${ }^{38}$ Anxiety could, however, also lead to curtailing activity levels because of perception of risk. Finally, anxiety itself could be a confounder for other factors associated with disability, but not explored here, such as impaired balance or falling. Further studies are needed to examine these and other possible mediators.

The main limitation of this paper is that the sample consists of disabled women. All participants had difficulty in at least 2 domains of functioning at the start of the study. However, because difficulty was assessed in a number of areas and the sample was large, we were able to look at the progression of disability in older women which is a strength of this study. Another limitation of this study is that anxiety symptoms, rather than anxiety disorders, are assessed. A clinical interview that assesses for specific anxiety disorders would be ideal. Nonetheless, the items were chosen from the well-validated SCL-90 because they are key symptoms of anxiety that are characteristic of most anxiety disorders. It is impressive that only 4 questions are able to identify a group at risk for the worsening of disability. Another strength of this study is that we were able to look at measures of disability in multiple areas that are ecologically valid for older adults. Finally, this study examined the role of anxiety as a risk for disability while controlling for depressive symptoms.

Anxiety is a common yet understudied problem for many older adults. This study found that anxiety is prevalent and is independently associated with the progression of disability in older adults, even after statistically controlling for confounding variables. Women with anxiety symptoms were $28 \%$ to $67 \%$ more likely to demonstrate greater functional difficulty than women without anxiety. This suggests that anxiety needs to be given more attention. Our results need to be followed with trials that test the impact of the treatment of anxiety on the delay or even prevention of disability.

\section{Acknowledgements}

The Women's Health and Aging Study I was supported by contracts N01-AG-1-2112 and AG-09834 from the National Institute on Aging to Dr. Fried and The Johns Hopkins University. The work of Dr. Brenes was supported through the Brooks Scholar in Academic Medicine Award and by NIMH grant MH65281. 


\section{References}

1. Pope AM, Tarlov AR. Disability in America: A National Agenda for Prevention. Washington, DC: National Academy Press, 1991,pg. 79.

2. Kessler RC, DuPont RL, Berglund P, et al. Impairment in pure and comorbid generalized anxiety disorder and major depression at 12 months in two national surveys. Am J Psychiatry 1999;156:19151923. [PubMed: 10588405]

3. Marcus SC, Olfson M, Pincus HA, et al. Self-reported anxiety, general medical conditions, and disability bed days. Am J Psychiatry 1997;154:1766-1768. [PubMed: 9396962]

4. Ormel J, Oldehinkel T, Brilman E, et al. Outcome of depression and anxiety in primary care. A threewave 3 1/2-year study of psychopathology and disability. Arch Gen Psychiatry 1993;50:759-766. [PubMed: 8215800]

5. Preisig M, Merikangas KR, Angst J. Clinical significance and comorbidity of subthreshold depression and anxiety in the community. Acta Psychiatr Scand 2001;104:96-103. [PubMed: 11473502]

6. Wittchen HU, Kessler RC, Beesdo K, et al. Generalized anxiety and depression in primary care: Prevalence, recognition, and management. J Clin Psychiatry 2002;63:24-34. [PubMed: 12044105]

7. Salaffi F, Cavalieri F, Nolli M, et al. Analysis of disability in knee osteoarthritis. Relationship with age and psychological variables but not with radiographic score. J Rheumatology 1991;18:1581-1586.

8. Bond J, Gregson B, Smith M, et al. Outcomes following acute hospital care for stroke or hip fracture: how useful is an assessment of anxiety or depression for older people? Int J Geriatr Psychiatry 1998;13:601-610. [PubMed: 9777424]

9. DeBeurs E, Beekman ATF, VanBalkom AJLM, et al. Consequences of anxiety in older persons: Its effects on disability, well-being and use of health services. Psychol Med 1999;29:583-593. [PubMed: 10405079]

10. Tinetti ME, Inouye SK, Gill TM, et al. Shared risk-factors for fall, incontinence, and functional dependence: Unifying the approach to geriatric syndromes. JAMA 1995;273:1348-1353. [PubMed: 7715059]

11. Sullivan MD, LaCroix AZ, Baum C, et al. Functional status in coronary artery disease: A one-year prospective study of the role of anxiety and depression. Am J Med 1997;103:348-356. [PubMed: 9375701]

12. Cumming RG, Salkeld G, Thomas M, et al. Prospective study of the impact of fear of falling on activities of daily living, SF-36 scores, and nursing home admission. J Gerontol A Biol Sci Med Sci 2000;55A:M299-M305. [PubMed: 10819321]

13. Murphy SL, Williams CS, Gill TM. Characteristics associated with fear of falling and activity restriction in community-living older persons. J Am Geriatr Soc 2002;50:516-520. [PubMed: 11943049]

14. Ried LD, Johnson RE, Gettman DA. Benzodiazepine exposure and functional status in older people. J Am Geriatr Soc 1998;46:71-76. [PubMed: 9434668]

15. Wang PS, Bohn RL, Glynn RJ, et al. Hazardous benzodiazepine regimens in the elderly: effects of half-life, dosage, and duration on risk of hip fracture. Am J Psychiatry 2001;158:892-898. [PubMed: 11384896]

16. Newsom JT, Schulz R. Social support as a mediator in the relation between functional status and quality of life in older adults. Psychol Aging 1996;11:34-44. [PubMed: 8726368]

17. Guralnik JM, Fried LP, Simonsick EM et al. The Women's Health and Aging Study: Health and Social Characteristics of Older Women with Disability. Bethesda, MD: National Institute on Aging; 1995. www.nia.nih.gov/health/pubs/whasbook/tablcont.htm

18. Folstein MF, Folstein SE, McHugh PR. "Mini-mental state". A practical method for grading the cognitive state of patients for the clinician. J Psychiatr Res 1975;12:189-198. [PubMed: 1202204]

19. Derogatis LR, Lipman RS, Rickels K, et al. The Hopkins Symptom Checklist (HSCL): a self-report symptom inventory. Behav Sci 1974;19:1-15. [PubMed: 4808738]

20. Yesavage JA, Brink TL, Rose TL, et al. Development and validation of a geriatric depression screening scale: A preliminary report. J Psychiatr Res 1983;171:37-49.

21. Penninx BWJH, Guralnik JM, Simonsick EM, et al. Emotional vitality among disabled older women: The Women's Health and Aging Study. J Am Geriatr Soc 1998;46:807-815. [PubMed: 9670865] 
22. Penninx BWJH, Guralnik JM, Bandeen-Roche K, et al. The protective effect of emotional vitality on adverse health outcomes in disabled older women. J Am Geriatr Soc 2000;48:1359-1366. [PubMed: 11083309]

23. Volpato S, Blaum C, Resnick H, et al. Comorbidities and impairments explaining the association between diabetes and lower extremity disability. Diabetes Care 2002;25:678-683. [PubMed: 11919124]

24. Volpato S, Ferrucci L, Blaum C, et al. Progression of lower-extremity disability in older women with diabetes. Diabetes Care 2002;26:70-75. [PubMed: 12502660]

25. Penninx BWJH, Seveille S, Ferrucci L, et al. Exploring the effect of depression on physical disability: Longitudinal evidence from the established Populations for Epidemiologic Studies of the Elderly. Am J Public Health 1999;89:1346-1352. [PubMed: 10474551]

26. Pahor M, Salive ME, Brown SL. Medication use. In: Guralnik JM, Fried LP, Simonsick EM et al., eds. The Women's Health and Aging Study: Health and Social Characteristics of Older Women with Disability. Bethesda, MD: National Institute on Aging, 1995, pp 162-169. www.nia.nih.gov/health/ pubs/whasbook/tablcont.htm

27. Guralnik JM, Simonsick EM, Ferrucci L, et al. A short physical performance battery assessing lower extremity function: Association with self-reported disability and prediction of mortality and nursing home admissions. J Gerontol A Biol Sci Med Sci 1994;40:85-94.

28. Psaty BM, Lee M, Savage PJ, et al. Assessing the use of medications in the elderly: Methods and initial experience in the Cardiovascular Health Study. J Clin Epidemiol 1992;45:683-692. [PubMed: 1607909]

29. Forsell Y, Winblad B. Feelings of anxiety and associated variables in a very elderly population. Int J Geriatr Psychiatry 1998;13:454-458. [PubMed: 9695033]

30. Mehta KM, Simonsick EM, Penninx BWJH, et al. Prevalence and correlates of anxiety symptoms in well- functioning older adults: Findings from the health aging and body composition study. $\mathrm{J}$ Am Geriatr Soc 2003;51:499-504. [PubMed: 12657069]

31. Astrom M. Generalized anxiety disorder in stroke patients. A 3-year longitudinal study. Stroke 1996;27:270-275. [PubMed: 8571422]

32. Kessler RC, Berglund P, Demler O, et al. the epidemiology of major depressive disorder: Results from the National Comorbidity Survey Replication (NCS-R). JAMA 2003;289:3095-3105. [PubMed: 12813115]

33. Regier DA, Rae DS, Narrow WE, et al. Prevalence of anxiety disorders and their comorbidity with mood and addictive disorders. Br J Psychiatry 1998;173(Suppl 34):24-28.

34. Lenze EJ, Rogers JC, Martire LM, et al. The association of late-life depression and anxiety with physical disability: A review of the literature and prospectus for future research. Am J Geriatr Psychiatry 2001;9:113-135. [PubMed: 11316616]

35. Jonas BS, Franks P, Ingram DD. Are symptoms of anxiety and depression risk factors for hypertension? Longitudinal evidence from the National Health and Nutrition Examination Survey I Epidemiologic Follow-up Study. Arch Fam Med 1997;6:43-49. [PubMed: 9003169]

36. Paterniti S, Alperovitch A, Ducimetiere P, et al. Anxiety but not depression is associated with elevated blood pressure in a community group of French elder. Psychosom Med 1999;61:77-83. [PubMed: 10024070]

37. Kubzansky LD, Kawachi I, Weiss ST, et al. Anxiety and coronary heart disease: A synthesis of epidemiological, psychological, and experimental evidence. Ann Behav Med 1998;20:47-58. [PubMed: 9989308]

38. Kiecolt-Glaser, McGuire L, Robles TF, et al. Emotions, morbidity, and mortality: New perspectives from psychneuroimmunology. Annu Rev Psychol 2002;53:83-107. [PubMed: 11752480] 


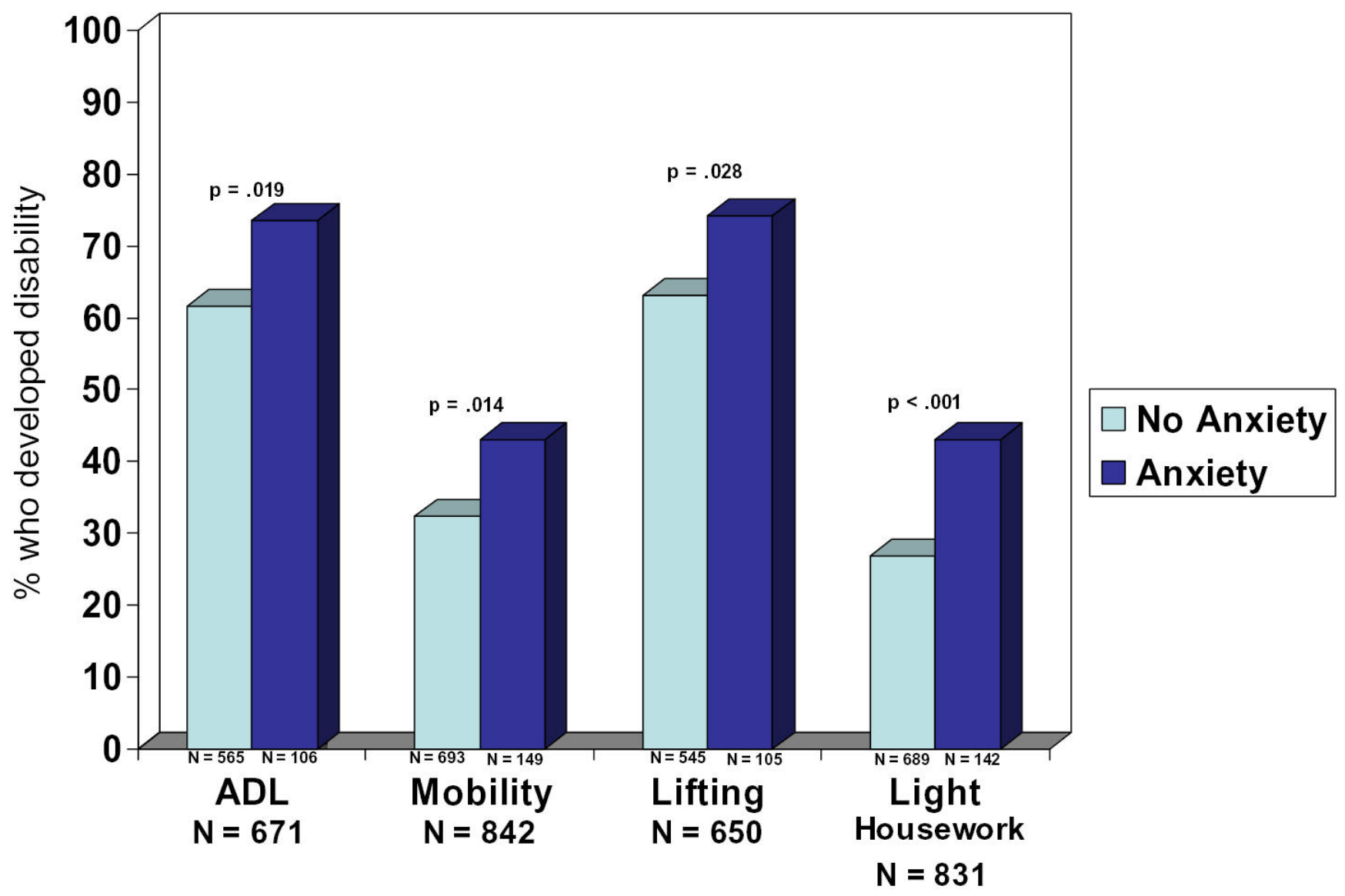

Figure 1.

Anxiety and the progression of disability. 
Table 1

Sociodemographic and health-related characteristics associated with anxiety: Women's Health and Aging Study $\mathrm{I}(\mathrm{N}=1,002)$.

\begin{tabular}{|c|c|c|c|}
\hline Variable & No anxiety $(N=812)$ & Anxiety (N = 190) & p value \\
\hline Age (M, SD) & $78.3(8.0)$ & $78.4(8.4)$ & .94 \\
\hline Race (\% African American) & $30.3 \%$ & $22.6 \%$ & .04 \\
\hline Marital status (\% married) & $20.8 \%$ & $22.1 \%$ & .70 \\
\hline Education $(\mathrm{M}, \mathrm{SD})$ & $9.9(4.7)$ & $9.9(6.9)$ & .94 \\
\hline Vision (\% with problem) & $15.6 \%$ & $22.1 \%$ & .03 \\
\hline Hearing ( $\%$ with problem) & $20.1 \%$ & $24.7 \%$ & .16 \\
\hline Number of diseases (M, SD) & $2.0(1.4)$ & $2.5(1.4)$ & .01 \\
\hline $\mathrm{BMI}(\mathrm{M}, \mathrm{SD})$ & $28.5(6.8)$ & $27.8(6.8)$ & .23 \\
\hline Summary performance score $(\mathrm{M}, \mathrm{SD})$ & $6.1(3.2)$ & $5.4(3.4)$ & $<.001$ \\
\hline Depressive symptoms (\% scoring $\geq 10$ ) & $23.6 \%$ & $66.3 \%$ & $<.001$ \\
\hline Benzodiazepine use (M, SD) & $7.1 \%$ & $15.8 \%$ & $<.001$ \\
\hline Physical activity (\% active) & $14.9 \%$ & $11.9 \%$ & .19 \\
\hline Emotional support (\% had enough in prior year) & $74.9 \%$ & $47.4 \%$ & $<.001$ \\
\hline Number of domains of disability (M, SD) & $2.98(0.86)$ & $3.36(0.78)$ & $<.001$ \\
\hline Psychotropic medication use & $16.5 \%$ & $27.9 \%$ & $<.001$ \\
\hline
\end{tabular}

* Note: Psychotropic medications include barbituates, monamine oxidase inhibitors, selective serotonin reuptake inhibitors, serotonin and norepinephrine reuptake inhibitors, trazadone, and tricyclics, and were used on a routine or prn basis. 
Table 2

Anxiety as a predictor of the development of disability: The Women's Health and Aging Study I.

\begin{tabular}{|c|c|c|c|c|}
\hline & ADL disability & Mobility disability & Lifting disability & Light housework disability \\
\hline Number of events & $426(63.5 \%)$ & $289(34.3 \%)$ & $422(64.9 \%)$ & $246(29.6 \%)$ \\
\hline Number of cases & 671 & 842 & 650 & 831 \\
\hline \multicolumn{5}{|l|}{ Model 1} \\
\hline HR & 1.40 & 1.41 & 1.54 & 1.77 \\
\hline $95 \% \mathrm{CI}$ & $1.10-1.79$ & $1.06-1.86$ & $1.20-1.97$ & $1.32-2.37$ \\
\hline $\mathrm{p}$ & .007 & .017 & .001 & $<.001$ \\
\hline \multicolumn{5}{|l|}{ Model 2} \\
\hline HR & 1.41 & 1.20 & 1.23 & 1.56 \\
\hline $95 \% \mathrm{CI}$ & $1.08-1.84$ & $0.90-1.63$ & $0.94-1.60$ & $1.14-2.14$ \\
\hline $\mathrm{P}$ & .013 & .228 & .128 & .005 \\
\hline \multicolumn{5}{|l|}{ Model 3} \\
\hline \multicolumn{5}{|l|}{ Emotional support } \\
\hline HR & 1.41 & 1.26 & 1.25 & 1.59 \\
\hline $95 \% \mathrm{CI}$ & $1.07-1.84$ & $0.92-1.71$ & $0.96-1.64$ & $1.16-2.19$ \\
\hline $\mathrm{p}$ & .013 & .145 & .101 & .004 \\
\hline \multicolumn{5}{|l|}{ Benzodiazepine use } \\
\hline HR & 1.00 & 1.07 & 1.79 & 0.79 \\
\hline $95 \% \mathrm{CI}$ & $0.70-1.42$ & $0.73-1.59$ & $1.28-2.52$ & $0.50-1.26$ \\
\hline $\mathrm{p}$ & .98 & .72 &. .001 & .32 \\
\hline \multicolumn{5}{|l|}{$\begin{array}{l}\text { Psychotropic } \\
\text { medication use }\end{array}$} \\
\hline HR & 1.01 & 0.91 & 1.00 & 1.17 \\
\hline $95 \% \mathrm{CI}$ & $0.79-1.30$ & $0.66-1.14$ & $0.78-1.27$ & $0.85-1.60$ \\
\hline $\mathrm{p}$ & .92 & .54 & .98 & .33 \\
\hline
\end{tabular}

HR = Hazard Risk; CI = Confidence Interval

Model 1: Unadjusted

Model 2: Adjusted for age, race, vision, \# of diseases, physical performance, and depressive symptoms

Model 3: Adjusted for age, race, vision, \# of diseases, physical performance, depressive symptoms, and individual mediator 